International Journal of Advanced Trends in Computer Science and Engineering

Available Online at http://www.warse.org/IJATCSE/static/pdf/file/ijatcse01762018.pdf

https://doi.org/10.30534/ijatcse/2018/01762018

\title{
Wireless sensor Network based Industrial Automation using Internet of Things (IoT)
}

\author{
${ }^{1}$ S.V.R.K.Rao, ${ }^{2}$ M.Saritha Devi, ${ }^{3}$ A.R.Kishore, $\quad{ }^{4}$ Praveen Kumar \\ $1,2,3 \& 4$ Department of ECE, Godavari Institute of Engineering \& Technology, Rajahmundry, A.P, India
}

\begin{abstract}
In this project, the sensor related information will be transmitted to the user by avoiding collision of IoT. The Internet of Things is the software, things embedded with electronics, sensors and network connectivity. In industries, most of the workers will lose their lives because of not having any safety cautions or alarm indications. For example, an alarm indicating the emergency of high temperatures and high humidity in work area. This sometimes results in damage of machineries too. This project solves the situation by providing an alarm/Buzzer indication whenever temperature or humidity increases in the work area. System user frequently notified with sensors data and if any high temperature/humidity values arise, an alarm or buzzer will indicate or caution the workers to be more alert in the work area. Some of works in industry should follow the temperature and humidity values are in certain range for reliable output. If temperature and humidity sensors values are exceeds then buzzer will horns. The main advantage of IOT based IWSN is data transmission without collision, safety and secured.
\end{abstract}

Keywords: Internet of things (IOT), wireless sensor networks, temperature and humidity sensor.

\section{INTRODUCTION}

Now a day a broad range of industrial IoT requisitions have been improved and organized. Evolution begins from RFID method that permits microchips to transmit the reorganization data to an observer by wireless communications. Through utilizing RFID readers, individuals could detect, track, and observe whatever objects attached with RFID tags naturally. Another innovation will be the WSNs (wireless sensor networks) that mostly utilize interconnected intelligent sensors to sense and screening. Its provisions incorporate environmental monitoring, traffic monitoring, and industrial monitoring. Both WSN and RFID would use to improve IoT.

There are numerous things we hear about industrial IoT as it is new developing method. We utilize sensors to constantly monitor industry appliances [1] that are highly difficult to control by human. We are going to improve auto-monitoring system to produce alert and notification through SMS and email on any digital (Computer and smart phone) device. Current advances in wireless sensing method encourage the additional optimization and development of the service provision processes and product.

The IWSN (Industrial wireless sensor networks) are a developing class of WSN, which appearances particular imperatives interfaced to the particularities of the mechanical production. For these terms, IWSNs countenances a few tests like the robustness sand reliability in harsh environments, and also the capacity to appropriately perform and attain the objective over parallel with every last one of other mechanical procedures. IWSN [2] results ought to be versatile, straightforward to use and install low cost, long lifetime gadgets indeed, the blending of prerequisites hard to meet. Dependent on the particular prerequisites of the industrial production, the Industrial wireless sensor networks requisitions could be ordered into 3 groups:

\subsection{Environmental sensing}

This bunch usually signifies the widest field of WSN provision these days. The IWSN requisitions for environmental sensing cover the issues of water, air pollution, however covers the generation material pollution checking also. In addition, in unsafe environments, there are various requirements for fire sensing, surge sensing. Lastly, the security problems happen in markets with challenging service providers and product providers, [3]-4] where IWSN are utilized for point of the interest, barrier monitoring, and area.

\subsection{Condition monitoring}

This bunch usually covers the issues of structural condition monitoring, giving both the machine condition monitoring and structure health data including probable automatic support. Consequently, this assembly of IWSN requisitions is crucial for the production in the whole the extensions of business.

\subsection{Process automation}

The most recent assembly of provisions gives the clients with the majority of the data in regards the assets for the production and service provision. Lastly, the most significant issue from the client viewpoint will be the production execution monitoring, assessment and develop that are attained through IWSNs. The basic overview of the system shown the figure 1 . 


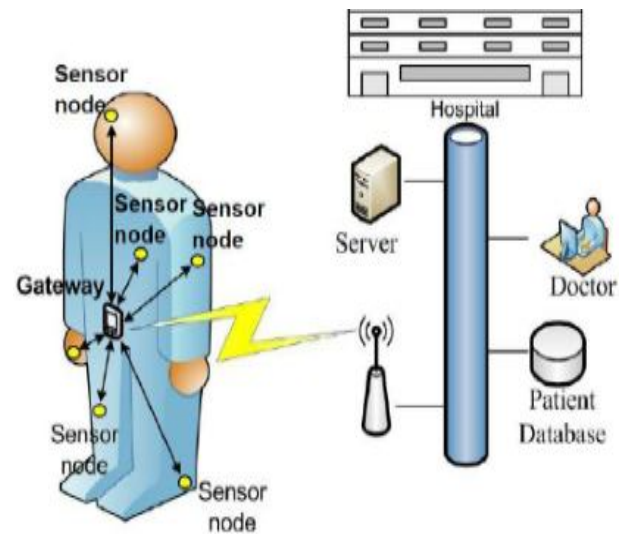

Figure 1: Wireless sensor body network Architecture

\section{LITERATURE REVIEW}

The idea of the web from claiming things might have been presented by those parts of the radio recurrence ID number advancement group keeping in 1999. This particular idea is exceptionally prominent due to Growth about versatile devices, inserted Furthermore constant communication, and cloud registering Furthermore information analytics. The web from claiming things is a system about physical Questions is installed for electronics in the figure 2 product also sensors hosting the capacity on gather information starting with that planet around us Furthermore impart information crosswise over the web. Web from [5] claiming things innovation may be creating will rearrange normal exercises Furthermore diminished the manual work.

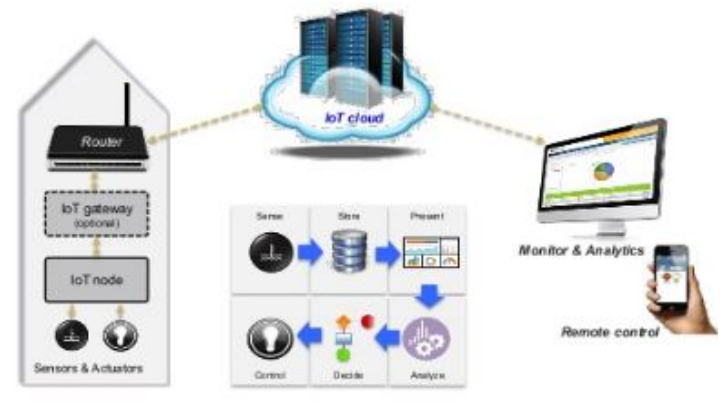

Figure 2: IOT Applications

\section{EXISTING SYSTEM}

In Existing system, the architecture designed to improve important advantages such as safety and security, platform independency, performance scalability, and product life cycle in Industrial environment. The Industrial wireless sensor network stacks with multiprocessor support based on real time operating system offers most advantages for industry in terms of above mentioned designed issues. An implemented Wireless
HART stack has established the feasibility of the architecture. So that the design is based on the three principles.

The first principle is Normalized inter layer interface. It acts as the communication [6]-[7] and information access interfaces among layers are normalized. The $2^{\text {nd }}$ principle of the architecture is also known as serialization layer, it operates as a transparent channel in among the two neighbor layers. It supports like after eliminating the serialization layer they might work correctly without any change. In particular, each layer in the stack core has at least one thread and dedicated mailbox. These interactions are classified into two types.

1. To modify configuration or status of one layer

2. To send or receive a packet

The third principle is also known as cross layer information synchronization to help flexible segregating of layers, the only one model for one layer to access the data in another layer is through the mailbox of NILI. To decrease the overhead, they are four flexible mechanisms designed for information updating [12].

1. Periodical polling, 2.periodical reporting, 3.even driven notification, 4.instant request

In this existing system power consumption is potential issue, real time operating system based architecture for industrial wireless sensor network with multiprocessor support is data should transfer between two processors without collision and loss of information [13] This system cannot transfer information at a time for industry environment.

\section{PROPOSED SYSTEM}

In this proposed system used the lpc2148 micro controller as main device to communicate with the temperature sensor and humidity sensor. The sensors values information sends to the webpage and then plot the sensor data in graphical statistics. [8]-[10] The information will update to the user by graphical analysis and also buzzer horns if values exceeds . Not only user but also exceeds values information should provide in industrial environment by displaying values on LCD shown in the block diagram in figure 3. And if any of the sensor values exceeds, the industry user can alert the workers for prevention methods also information should be secured with the user id for webpage it cannot copied for any others [11]. 


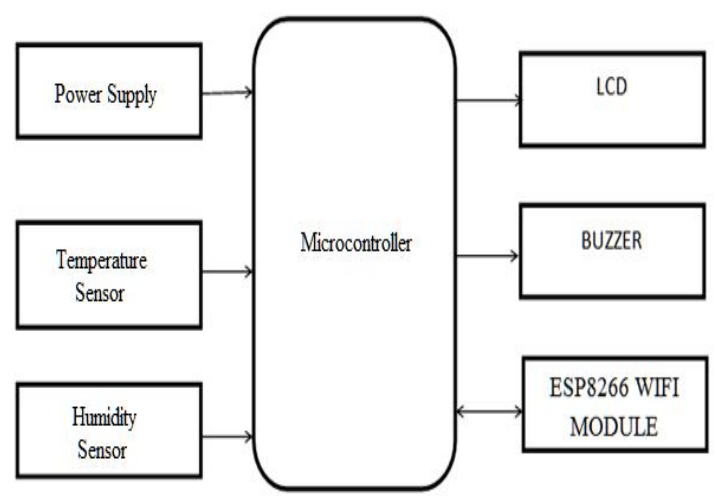

Figure 3: Block diagram of proposed system

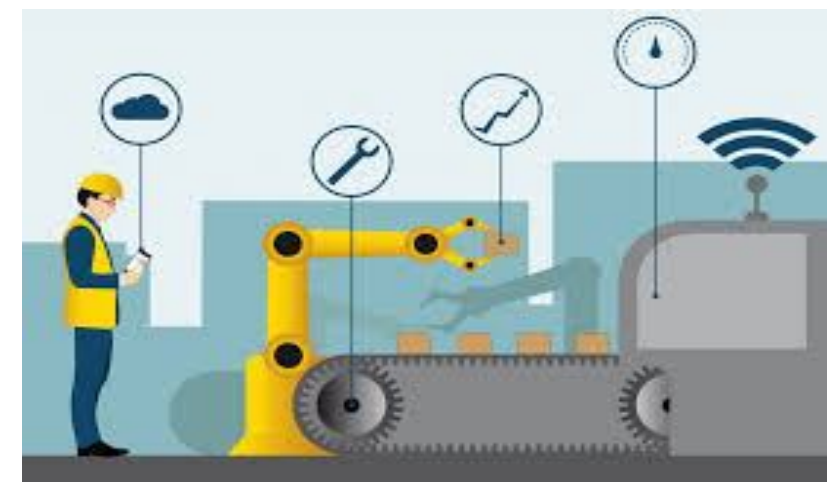

Figure 4: Proposed systems Model

\subsection{Temperature sensor}

The sensor utilized in this project is LM35 Precision centigrade Temperature sensor. It transfers temperature value into electrical signals. Primarily this temperature values has to be read and send to the microcontroller and updating on the webpage [9]. The LM35's straight yield, low yield impedance, and correct characteristic arrangement make interfacing to readout. The external calibration is not necessary for this sensor as in figure 4.1. It has low self-warming under $0.1^{\circ} \mathrm{C}$ in static air.

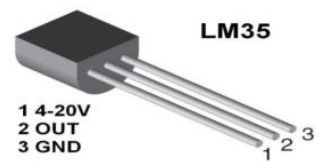

Figure 4.1: LM35 Temperature sensor

\subsection{Humidity Sensor}

A humidity sensor is used to sense, measure and report the air temperature and the dampness. The ratio of dampness in the air to the highest amount of dampness at a specific air temperature will be known as relative moistness. The relative moistness gets a critical factor, when searching for solace. Humidity sensors operate through identifying progressions that modify the temperature in the air. The humidity sensors have three fundamental sorts: capacitive, thermal, and resistive shown in below figure 4.2. These 3 sorts of sensors screen moment progressions in the environment to compute the humidity in the air

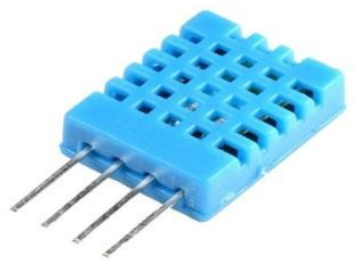

Figure 4.2: Humidity sensor

\subsection{ESP8266 WI-FI MODULE:}

The ESP8266 Wi-Fi module will be a self-contained SOC with incorporated TCP/IP protocol stack that might provide any microcontroller entry to your Wi-Fi system as shown in figure 4.3. The ESP8266 may be fit for either hosting an application or offloading all Wi-Fi networking functions from an alternate requisition processor. This module has a capable sufficient onboard processing and storage capability that permits it with make coordinated [12] with the sensors and other provision particular gadgets through its GPIOs with minimum improvement up-front and minimal loading during runtime.

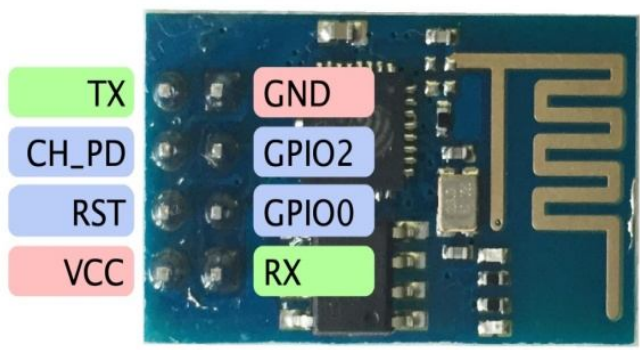

Figure 4.3: ESP8266 WIFI module

\section{IMPLEMENTATION}

\subsection{Flow chart}

The system way of working and monitoring the data it showing in figure 5 . 


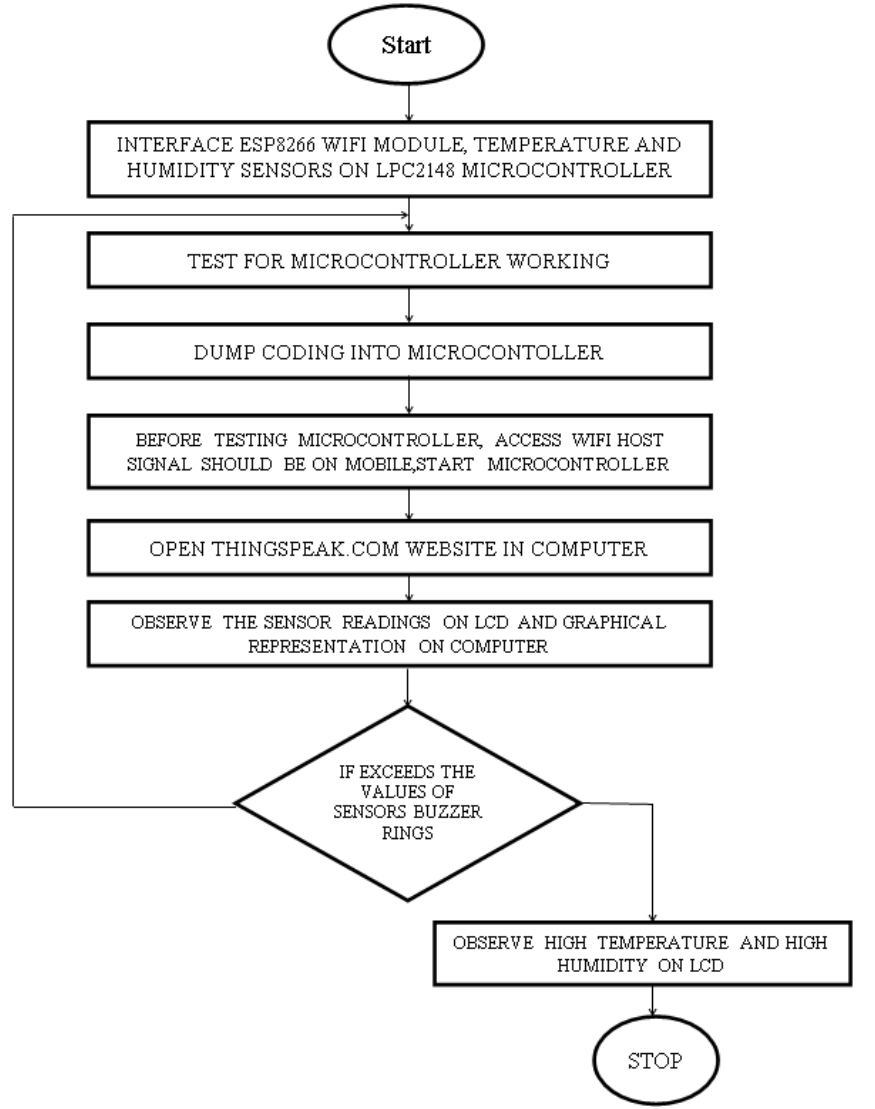

Figure 5: flow chart of the proposed system

The proposed Architecture flowchart states the temperature and humidity sensors values to the user through Internet of things (IOT). Initially we interface temperature and humidity sensors, ESP8266 Wi-Fi module, LCD, buzzer with LPC2148 microcontroller shown in the figure 5.1. Then start the microcontroller by giving power supply [13]

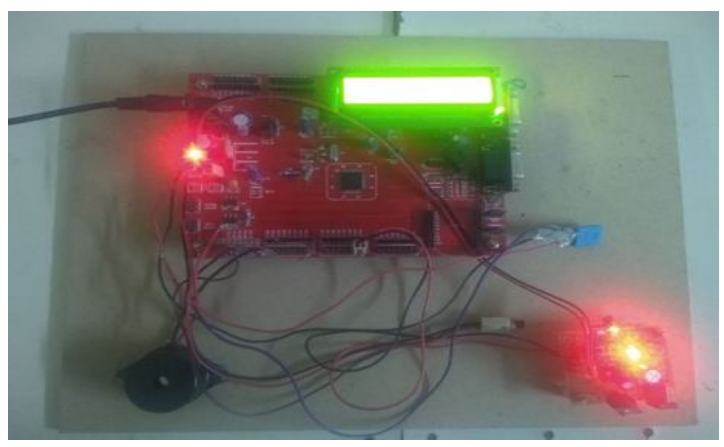

Figure 5.1: System setup with hardware

\section{RESULTS}

Temperature sensor values in graphical representation using internet of thing as shown the result in figure 5.2.

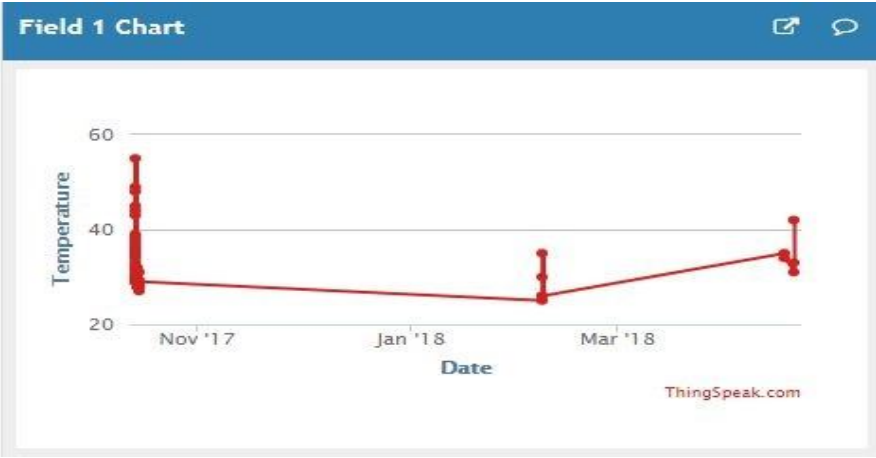

Figure 5.2: Humidity sensor values in graphical representation

It reads sensors readings given to $\mathrm{Wi}-\mathrm{Fi}$, if temperature or humidity values increases then buzzer rings and high temperature and humidity will display on LCD as shown the figure 5.3.

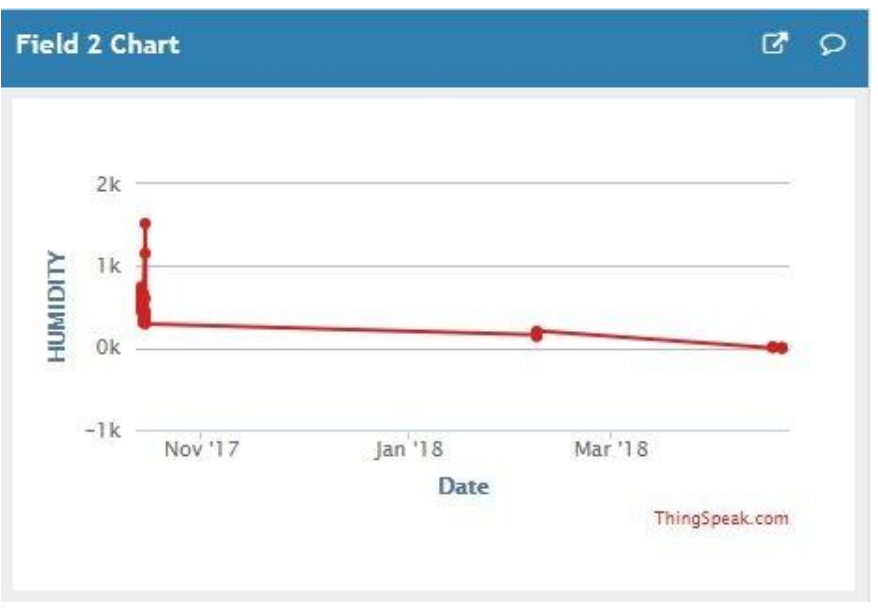

Figure 5.3: Graphical representations are charts for temperature and humidity sensor values.

\section{CONCLUSION}

The proposed model helps the industries for maintaining healthy work environment and avoiding damage of machineries /Industry infrastructures. Information will be processed on time without having any collisions with IOT. By this model/project industries to be benefitted with many advantages like
a) Improves Performance
b) Increase in Productivity
c) Avoiding injuries /Accidents
d) Avoiding Damage of Infrastructures/Machineries.

\section{REFERENCES}

[1] Zhibo pang, Kanyu, Johan akerberg, Mikelgidlund, "RTOS Based Architecture For Industrial Wireless Sensor Network Stacks With Multiprocessor Support”, IEEE 2013 Conference. 
[2] Kerberg.J, Gidlund.M, Bjorkman.M, "Future Research Challenges In Wireless Sensor And Actuator Networks Targeting Industrial Automation",IEEEInt.con.on Industrial informatics(INDIN),2011,410-415.

[3] ISA100 Standard, International society of Automation,www.isa.org/isa100.

[4] Xiuming Zhu, song han, Mok.A, Dejichen, Nixon, hardware challenges and their resolution in advancing WirelessHART, IEEE Int.con.on Industrial informatics(INDIN), 2011,416-421.

[5] H.-J. Korber, H. Wattar, and G. Scholl, Modular wireless real-time sensor/actuator network for factory automation applications. Industrial In-formatics, IEEE Transactions on, 3(2):111-119, May 2007.

[6] Li Da Zu" Internet of Things in Industries: A Survey" IEEE Transactions on Industrial Informatics, vol. 10, no. 4, November 2014

[7] L. L. Bello, O. Mirabella, and A. Raucea, "Design and implementation of an educational testbed for experiencing with industrial communication networks," IEEE Trans. Ind. Electron., vol. 54, no. 6, pp. 3122-3133,Dec. 2007. https://doi.org/10.1109/TIE.2007.907025

[8] D. Dzung, C. Apneseth, J. Endersen, and J. E. Frey, "Design and implementation of a real-time wireless sensor/actuator communication system,"'inProc. IEEE Conf., Emerg. Technol. Factory Autom., 2005, p. 442. https://doi.org/10.1109/ETFA.2005.1612710

[9] Sadeque Reza, Khan Professor Dr. M. S. Bhat, "GUI Based Industrial Monitoring and Control System”,IEEE paper, 2014

[10] Apoorva Deshpande, Ramnaresh Sharma," Multilevel Ensemble Classifier using Normalized Feature based Intrusion Detection System", International Journal of Advanced Trends in Computer Science and Engineering, Volume 7, No.5, Pp-72-76,2018.

[11] AshwiniDeshpande ,PrajaktaPitale , SangitaSanap"Industrial Automation using Internet of Things (IOT)", International Journal of Advanced Research in Computer Engineering \& Technology (IJARCET) Volume 5 Issue 2, February 2016.

[12] Geetesh Chaudhari, Sudarshan Jadhav, Sandeep Batule, Sandeep Helkar,"Industrial Automation using Sensing based Applications for Internet of Things", International Advanced Research Journal in Science, Engineering and Technology Vol. 3, Issue 3, March 2016

[13] Anilgantala, Dasari Swathi, J Sravana, Paparao Nalajala," Automatic License Plate Detection And Character Recognition In License Plate International Journal Of Advanced Trends In Computer Science And Engineering, Vol.5 , No.1, Pages : 46-50, (2016) 